\title{
Revista Signo: desafios da última década
}

\author{
Signo journal: challenges of the last decade
}

\section{Rosângela Gabriel}

Universidade de Santa Cruz do Sul - UNISC - Santa Cruz do Sul - Rio Grande do Sul - Brasil

\begin{abstract}
Resumo:O presente artigo, publicado por ocasião da comemoração dos 40 anos da revista Signo, desde sua criação em 1975, tem por objetivo registrar alguns aspectos da história da revista ao longo da última década, de 2005 a 2015. Nesse período, um dos fatos marcantes foi a aprovação do Programa de Pós-Graduação em Letras PPGL, da Unisc, cuja primeira turma teve início em 2005. A revista Signo, periódico voltado à publicação de artigos científicos na área de Letras - Linguística e Literatura foi incorporada à dinâmica do novo programa de pós-graduação e aos requisitos de qualificação de periódicos do Qualis Capes. Outro fato marcante do período foi a migração da revista do formato impresso (ISSN 0101-1812) para o formato eletrônico (ISSN 1982-2014), e as várias transformações decorrentes, dentre elas a interconectividade entre bases de dados por meio de indexadores e de ferramentas computacionais especializadas na identificação e acessibilidade de artigos científicos, dentre elas o DOI - Digital Objectldentifier. Por fim, o artigo propõe uma reflexão sobre alguns desafios da próxima década, dentre eles a internacionalização, a profissionalização e a sustentabilidade.
\end{abstract}

Palavras-chave:PPGLUnisc. Qualis Capes. Indexação.DOI.Internacio-nalização.

Abstract:The present article, published during the celebration of the 40th anniversary of the Signo journal, created in 1975, has the aim of registering some aspects of the journal's history over the last decade, from 2005 to 2015. In this period, one of the remarkable fact was the approval of the Post-Graduation in LetrasPrograme, of Unisc, whose first students' group started in 2005. The Signo journal, dedicated to publishing scientific articles in the área of Linguistic and Literature, was incorporated to the dynamic of the new graduation program and to the requirements of journal's qualification of Qualis Capes. Another remarkable fact of the period was the transition from the printed format (ISSN 0101-1812) to the electronic format (ISSN 1982-2014), and the several consequent transformations, among them the interconnectivity between databases via index systems and the computational tools designed to identify and to give access to scientific journals, among of them the DOI - Digital Object Identifier. Finally, the article proposes to consider some of the challenges of the next decade, namely the process of internationalization, professionalization and sustainability.

Keywords: PPGL Unisc. QualisCapes.Indexation. DOI.Internationalization. 


\section{Introdução}

A revista Signo foi fundada em 1975 pelo professor Dr. Ingo Voese, coordenador à época do CEPELL - Centro de Estudos e Pesquisas em Linguística e Literatura - da então Faculdade de Filosofia, Ciências e Letras de Santa Cruz, da qual também foiDiretor. Posteriormente, o professor Ingo foi Diretor Geral das Faculdades Integradas de Santa Cruz do Sul - FISC, origem da Universidade de Santa Cruz do Sul - UNISC. Com a criação da Universidade, a revista Signo continuou sendo mantida pelo CEPELL,agora ligado ao Departamento de Letras. Em reconhecimento ao pioneirismo do seu fundador, o volume 33, n. 54, jan-jun de 2008 da Signo, organizado pelo professor João Wanderley Geraldi, é dedicado ao professor Ingo Voese, falecido em 2007 (número disponível em https://online.unisc.br/seer/index.php/signo/issue/view /29).

No artigo que antecede a este, de autoria do professor Elenor Schneider,conhecemos um pouco da história dos primeiros trinta anos da revista Signo - de 1975 a 2005. No presente artigo, propomo-nos a resgatar aspectos importantes dos últimos 10 anos da revista Signo, de 2005 a 2015. Entretanto, é impossível falar dos últimos 10 anos da Signo sem ao mesmo tempo falar da história do Programa de PósGraduação em Letras da Universidade de Santa Cruz do Sul, doravante PPGL Unisc. Na próxima seção, vamos retomar um pouco da história do PPGL e de como sua história e a da revista Signo se (con)fundem.

\section{Revista Signo e Programa de Pós-Graduação em Letras: duas histórias que se (con)fundem}

O artigo 207 da Constituição Federal de 1988 prevê a indissociabilidade entre ensino, pesquisa e extensão. A Unisc, ao constituir-se como universidade em 1993, passou a investir esforços humanos e recursos financeiros para o desenvolvimento da pesquisa, associada ao ensino e à extensão. Já em 1994, foi constituída a primeira turma do Programa de
Pós-Graduação em Desenvolvimento Regional Mestrado e, em 1998, a primeira turma do Programa de Pós-Graduação em Direito - Mestrado. Ao mesmo tempo, houve incentivo institucional para que os professores da Unisc buscassem continuar sua formação em cursos de mestrado e doutorado. Assim, mestres e doutores se articularam em núcleos e grupos de pesquisa a partir de temas e projetos conjuntos, proporcionando as condições necessárias para a implantação de novos programas de pósgraduação stricto sensu (KIPPER, 2014, p. 202).

Em 2001, a Unisc lançou edital para seleção de dois projetos a serem apoiados pelo FUNDAP Fundo para o Desenvolvimento de ÁreasPrioritárias, que tinha por objetivo apoiar grupos de pesquisa com vistas à criação de novos projetos de mestrado. $\mathrm{O}$ projeto "Cognição e Leitura", coordenado pelos professores Ingrid Finger e Norberto Perkoski, foi um dos projetos contemplados por esse primeiro edital, cujo apoio consistia na previsão de horas para os professores dedicarem-se à construção do projeto de curso, contratação de secretária, espaço físico e material de expediente. Com o afastamento da professora Ingrid da instituição em 2002, a professora Rosângela Gabriel assumiu a coordenação adjunta do projeto. No início de 2004, o projeto de Mestrado em Letras foi encaminhado à Capes, tendo tido sua proposta recomendada pelo Conselho Técnico Científico em novembro de 2004, conforme Ofício no 462/2004, e seu reconhecimento através da Portaria no 1.919 , de 3 de junho de 2005, publicada no Diário Oficial da União em 06 de junho de 2005. A primeira turma do PPGL iniciou suas atividades em março de 2005, tendo ocorrido a primeira defesa em dezembro de 2006. Em julho de 2014, no décimo ano de funcionamento do curso, ocorreu a defesa da centésima dissertação de mestrado do PPGL Unisc.

O PPGL da Unisc integra a área de Letras e Linguística da Capes, e possui uma área de concentração: Leitura e Cognição. Desde sua origem, caracterizou-se pela busca de uma visão transdisciplinar do conhecimento, agregando em seu grupo de professores-pesquisadores profissionais com formação na área de Letras - Literatura e 
Linguística, mas também Comunicação, Educação, Filosofia, Psicologia, dentre outras, tendo como objetivo geral "consolidar a pesquisa nas áreas de Leitura e Cognição na UNISC, a fim de qualificar recursos humanos para atuarem na docência, na pesquisa e em atividades profissionais específicas do acadêmico de Letras e áreas afins" (UNISC, 2015).

A aprovação do curso de mestrado constituiuse em um marco para o Departamento de Letras, ao qual muitos dos professores do PPGL estão vinculados, e ao qual o CEPPEL, responsável pela publicação da Signo, está vinculado. O novo cursode mestrado trouxe também uma nova consciência em relação ao funcionamento do Sistema Nacional de Pós-Graduação - SNPG e aos critérios de acompanhamento e avaliação dos programas de pósgraduação pela Capes - Coordenação de Aperfeiçoamento de Pessoal de Nível Superior, fundação responsável pela expansão e qualificação do sistema de pós-graduação brasileiro, ligada ao Ministério da Educação.

Dentre as várias ações da Capes, está a criação do sistema Qualis de avaliação de periódicos científicos, cuja implantação teve início em 1998, em vista da necessidade de avaliação da qualidade das publicações resultantes dos programas de pósgraduação brasileiros. De lá para cá, o Qualis periódicos tem sido alvo de muitas críticas e reformulações, mas continua sendo considerado, pela maioria dos coordenadores de programas de pósgraduação, um sistema válido, que deve ser mantido e aperfeiçoado (BONINI, 2004; MACIEL; ROCHA NETO, 2012).

O Qualis Capes classifica os periódicos em 7 estratos: A1 e A2 (periódicos de reconhecida relevância internacional), e B1 a B5 (periódicos de relevância nacional, sendo B1 o estrato superior dessa escala). Interessante observar que a avaliação dos periódicos não abrange todos os periódicoscientíficos publicados no Brasil ou no mundo, tomando como ponto de partida a base de dados fornecida por outro instrumento de avaliação da Capes: o Relatório Coleta de Dados, substituído em 2014 pelo sistema Sucupira (BRASIL/MEC/CAPES, 2015).

Assim, a crescente compreensão dos critérios de avaliação de periódicos pelo Qualis Capes colocou novos desafios à revista Signo e ao Departamento de Letras da Unisc. Desde a sua criação, em 1975, os editores responsáveis pela revista, assim como os membros do Conselho Editorial e os pareceristas ad hoc, realizavam a avaliação do mérito dos artigos submetidos, em especial quanto à qualidade do conteúdo, à correção e adequação da linguagem e à observância das normas da ABNT - Associação Brasileira de Normas Técnicas.

Entretanto, com a criação do PPGL Unisc e o natural reconhecimento da revista Signo como um instrumento de divulgação das pesquisas realizadas no âmbito desse e de outros programas de pósgraduação brasileiros e internacionais, os editores passaram a dar atenção também aos critérios estabelecidos pela área de avaliação da revista no sistema Qualis Capes. A título de exemplificação, o Documento da Área de Letras e Linguística de 2013 e o Relatório de Avaliação Trienal 2013 (BRASIL/MEC/CAPES, 2015) prevêemparâmetros gerais de avaliação e critérios para classificação dos periódicos nos respectivos estratos, que vão sendo tomados de forma cumulativa à medida que se passa dos estratos mais baixos aos mais altos. Esses critérios são aperfeiçoados continuamente e uma nova classificação é divulgada a cada triênio de avaliação da Capes. A revista Signo, que em 2005 não figurava no Qualis Capes, foi classificada na área de Letras e Linguística como B4 em 2008, e B2 em 2011 (BRASIL/MEC/CAPES, 2015), reiterando-se o empenho dos editores da Signo para que essa trajetória ascendente se mantenha.

\section{Do formato impresso à versão eletrônica}

Alunos de graduação, mestrandos e doutorandos, e mesmo jovens pesquisadores na faixa de 20 e 30 anos não vivenciaram e talvez nem consigam imaginar as mudanças ocorridas nas últimas décadas, resultantes da divulgação e 
incorporação da rede internacional de computadores - internet - em praticamente todos os aspectos da vida humana moderna. Se as pesquisas que deram origem à internet remontam à década de 1960, a popularização de seus usos é muito mais recente, por volta de 30 anos, com incrementos constantes nesse período, graças ao desenvolvimento de novos aplicativos e suportes físicos, com impactos que seriam considerados mera ficção científica décadas atrás.

A possibilidade de troca de informações por meio da WorldWide Web causou um efeito em cascata, não estabilizado até o presente momento, na editoração de revistas científicas em todo o mundo. A substituição do snail mail- smail ${ }^{1}$, ou seja, do correio tradicional, pelo correio eletrônico - email, proporcionou agilidade no processo de submissão de artigos (antes enviados impressos, com várias cópias em papel, e mais tarde em disquetes e cds), envio de arquivos a pareceristas, processo de revisão, etc.

O desenvolvimento de softwares desenhados para atender às demandas da editoração científica, como é o caso do SEER - Sistema Eletrônico de Editoração de Revistas, foi outro passo importante. Disponibilizado à comunidade científica em 2003, o SEER é a versão brasileira, traduzida e adaptada pelo Instituto Brasileiro de Informação em Ciência e Tecnologia (IBICT), do Open Journal Systems, software desenvolvido pela Universidade British Columbia para a construção e gestão de publicações periódicas eletrônicas (BRASIL/MCTI, 2015). Recomendado pela Capes, o SEER é atualmente utilizado por grande parte das revistas científicas brasileiras.

As revistas científicas da Unisc, ligadas à Edunisc, sob a coordenação da professora Helga Haas, e dentre elas a Signo, não ficaram alheias às vantagens oferecidas pela possibilidade de editoração e publicação eletrônica. Além da agilidade na editoração, a perspectiva de ampliação da abrangência das publicações que utilizam o formato eletrônico (virtualmente, qualquer lugar do planeta,

\footnotetext{
${ }^{1}$ Snail mail (correio lesma) é uma expressão bem humorada em inglês, que faz referência à lentidão característica do correio tradicional em oposição à agilidade do correio eletrônico.
}

desde que haja acesso à internet) foi um critério de peso. A publicação impressa, após todo o processo de leitura, seleção e editoração de artigos e organização de cada número, enfrentava a dificuldade de custo e mão de obra para envio dos exemplares aos assinantes e às bibliotecas parceiras. Assim, os 500, 800 ou 1000 exemplares impressos eram enviados por correio convencional e muitos exemplares ficavam estocados na universidade, sem chegar às mãos dos leitores para quem tinham sido produzidos. Após reflexão cuidadosa da comunidade acadêmica da Unisc, em 2007, ainda que sob o olhar reprovador dos amantes da versão impressa, a revista Signo, juntamente com as outras revistas da Unisc, passou a ser produzida e veiculada em ambiente eletrônico. Essa mudança de suporte criou a necessidade de adequação do ISSN da revista: 0101-1812 para a versão impressa; 1982-2014 para a versão online.

Passados oito anos da transição da versão impressa para a online, não resta dúvida de que a decisão tomada à época foi correta. Hoje é possível acessar e fazer download gratuito a partir do site da revista

http://online.unisc.br/seer/index.php/signo(UNISC/SIG NO, 2015) de cada um dos artigos publicados nos números 54 (volume 32, 2007) ao número 68 (volume 40, 2015), da Signo. Já para ter acesso aos artigos publicados na versão impressa, o leitor precisa ser bem mais persistente e buscar os artigos em papel nas bibliotecas conveniadas ou buscar uma versão escaneada na própria internet ou junto à biblioteca da Unisc.

\section{A editoração de revistas científicas em ambiente digital}

A facilidade de acesso aos artigos publicados na internet e o desenvolvimento de ferramentas de busca cada vez mais sofisticadas modificaram 0 comportamento de estudantes e pesquisadores, público alvo das revistas científicas. Se 20 anos atrás, as bibliotecas -amplosprédios mobiliados com grandes estantes e livros enfileirados - eram o local 
privilegiado da pesquisa bibliográfica, hoje o comportamento dos pesquisadores é outro. As bibliotecas continuam sendo importantes para a pesquisa de livros impressos e como local de estudo, mas a interconectividade entre bases de dados e ferramentas de busca online - por títulos, palavraschave, autores, assuntos, etc. - permite que o usuário faça o download de milhares de artigos eletrônicos e ebooks em seu computador, sem sair de sua sala.

Por isso, um dos desafios das revistas científicas eletrônicas é ter seus artigos indexados por importantes bases de dados, para que as ferramentas de busca encontrem os artigos e os ofereçam aos leitores. As bases indexadoras funcionam como certificados de garantia de que uma publicação é séria e segue padrões de qualidade reconhecidos, e não apenas uma reunião de artigos publicados na internet de forma inconsequente. Os administradores das bases indexadoras estabelecem critérios para inclusão de revistas em suas bases de dados, gerando uma série de demandas para os editores de revistas científicas.

No ano em que completa 40 anos, 2015, Signo está indexada nas seguintes bases de dados nacionais e internacionais:

- DOAJ - Directoryof Open Access Journals www.doaj.org, diretório online que indexa e proporciona o acesso a revistas científicas de acesso aberto (que não requerem pagamento para download dos artigos) de reconhecida qualidade, cujos artigos submetidos passem por avaliação por pares;

- Latindex - Sistema Regional de Informação online para Revistas Científicas da América Latina, Caribe, Espanha e Portugal - www.latindex.unam.mx, sistema de informação dedicado ao registro e difusão de revistas acadêmicas editadas nos países iberoamericanos, bem como a disseminação depadrões editoriais com vistas a elevar a qualidade dessas publicações, representada no Brasil pelo IBICT;

\section{ProQuestLinguisticsandLanguageBehavior}

Abstracts - LLBA - www.proquest.libguides.com/llba, base de dados que indexa a literatura internacional pertinente à área de linguística e disciplinas relacionadas às ciências da linguagem, incluindo fonética e fonologia, morfologia, sintaxe e semântica, bem como campos da linguística descritiva, histórica, comparativa, teórica, dentre outros;

- LivRe! Portal para periódicos de livre acesso na Internet - www.portalnuclear.cnen.gov.br, portal desenvolvido pela CNEN - Comissão Nacional de Energia Nuclear, através do CIN - Centro de Informações Nucleares, para facilitar a identificação e o acesso a periódicos eletrônicos de acesso livre na Internet;

- Sumários de Revistas Brasileiras www.sumarios.org, base indexadora de periódicos científicos brasileiros, mantida pela Fundação de Pesquisas Científicas de Ribeirão Preto (FUNPEC$\mathrm{RP}$ ), antes desenvolvido pelo Instituto Brasileiro de Informação em Ciências e Tecnologia (IBICT).

A revista Signo participa da rede de colaboração LATINOAMERICANA - Asociación de Revistas Literarias y Culturales http://mascipo.in2p3.fr/LATINOAMERICANA, criada em 2014, com os objetivos de estabelecer e impulsar critérios acadêmicos que fortaleçam a qualidade científica e editorial das revistas associadas à rede; promover o intercâmbio e a discussão de conteúdos e experiências que fortaleçam a cooperação acadêmica e editorial; e incrementar a difusão, visibilidade, reconhecimento e impacto das revistas integrantes da rede.

No sentido de ampliar a inserção internacional e acompanhar as demandas decorrentes da publicação em ambiente digital, a partir do volume 39, número 67, ano de 2014, os artigos publicados na revista Signo passam a ostentar o DOI - Digital Objectldentifier. O DOI é um identificador internacional de artigos científicos, mas também de livros, anais de eventos, teses, entre outros materiais de referência acadêmica. O DOI surgiu com o objetivo de assegurar a confiabilidade e autenticidade das referências citadas pelos autores. Ao lado dos metadados, como nome do autor, título do artigo, do periódico, ISSN, número, volume e ano de publicação, o DOI é uma informação exigida por muitos jornais eletrônicos internacionais com 0 objetivo de identificar com precisão uma determinada 
publicação científica. O DOI é uma sequência de 20 a 30 caracteres, indicando o diretório DOI (dx.doi.org), o prefixo e o sufixo do artigo (compõe o sufixo o nome do periódico, volume e número). Essa sequência em seu conjunto é única e não se repete em nenhuma outra referência internacional. O exemplo (1) mostra o DOI e a forma como essa informação deve ser citada em produções que fizerem referência futuramente a esse artigo (opcionalmente, pode-se usar a versão sintética do DOI, isto é, apenas o prefixo e o sufixo (no caso do exemplo abaixo: 10.17058/signo.v39i67.540):

(1) ZANOTTO, M. S. As múltiplas leituras da 'metáfora': desenhando uma metodologia de investigação. Signo. Santa Cruz do Sul, v. 39, n. 67, p. 3-17, jul./dez. 2014. http://dx.doi.org/10.17058/signo.v39i67.5409

O DOI é mantido e operado internacionalmente pela IDF - International DOI Foundation, que fornece a infraestrutura organizacional do sistema. Já o registro e as atualizações dos artigos, bem como outros serviços relacionados, são realizados pela CrossRef, uma associação internacional de editores científicos, sem fins lucrativos, cujos membros pertencem a mais de 80 países. Seu objetivo é promover o desenvolvimento e uso cooperativo de novas e inovadoras tecnologias a fim de acelerar e facilitar a pesquisa científica, interconectando as referências disponíveis em formato eletrônico. A CrossRef não armazena os textos na sua íntegra, mas funciona por um sistema de links, por meio do DOI e dos metadados fornecidos pelos editores de periódicos, que remetem aos textos completos. O resultado é uma rede composta em 2015 por 73 milhões de links, sendo $77 \%$ composto de artigos científicos, e os restantes $23 \%$ distribuídos entre livros, anais de eventos, teses, etc, de acordo com dados disponíveis no site da CrossRef (2015).

Graças a essa interconectividade, muitas revistas científicas oferecem aos seus leitores a possibilidade de não apenas conhecerem a referência completa de uma determinada obra citada, como nas referências tradicionais de livros e artigos impressos, mas a possibilidade de acessar o texto completo do artigo citado através de um único toque,já que a referência do artigo citado constitui-se em um hiperlink para a íntegra do artigo. Ainda por conta dessa conectividade, várias métricas passaram a fazer parte do universo da publicação científica, e algumas revistas informam juntamente com a referência do artigo, o número de vezes que um determinado artigo foi citado e em que artigos, o fator de impacto, e por meio de que bases de dados ele pode ser acessado (ver, por exemplo, as publicações da Elsevier).

A identificação e indexação dos artigos publicados na Signo através do DOI é um avanço significativo na história da revista. Com a utilização do DOI na identificação dos artigos da Signo esperamos, em um futuro próximo, poder também oferecer aos leitores da revista a facilidade de acesso às demais referências indexadas pela CrossRef. Esse avanço é fruto do esforço e cooperação de múltiplos atores, nomeadamente da Unisc, que elegeu a qualificação de seus periódicos científicos como uma das metas do PDI - Plano de Desenvolvimento Institucional 2013-2017 (ver Meta 9 - UNISC, 2013). Assim, as revistas da Unisc, ligadas a programas de pósgraduação stricto sensu, possuem-se a ampliar, no período referido do PDI, o reconhecimento de sua qualidade por meio do avanço nos estratos do Qualis Capes.

\section{Pensando no futuro: alguns desafios da próxima década}

Uma revista científica com 40 anos de existência, ao mesmo tempo em que comemora a vitória do pioneirismo e da persistência daqueles que engendraram essa história, precisa também projetar os desafios que se apresentam para os anos vindouros. Não se trata de ter a petulância de prever o futuro, mas sim de ter consciência de que alguns desafios que estão postos hoje precisam de ações de curto e médio prazo tendo em vista o panorama que se vislumbra

A revista Signo adota a revisão cega por pares (blindpeerreview) como metodologia para a seleção 
dos artigos submetidos, assim como a maioria das revistas científicas respeitadas (para uma discussãosobre a confiabilidade dessa metodologia, ver Li e Agha, 2015). Na revista Signo, essa avaliação é realizada em duas etapas: na primeira etapa, a Comissão Editorial da revista ou os organizadores de um número temático, ou de um dossiê, fazem a avaliação de todos os artigos submetidos a um determinado número, rejeitando aqueles que não apresentam as características mínimas de qualidade exigidas pela revista. Os artigos rejeitados são devolvidos aos autores, juntamente com um parecer sucinto esclarecendo as razões da rejeição. Já os artigos aprovados nessa primeira fase são enviados aos membros do Conselho Editorial ou a consultores ad hoc, a fim de que avaliem a qualidade da submissão ou ainda a sua pertinência a uma determinada temática, quando da organização de números temáticos. Esses avaliadores emitem um parecer justificado, favorável ou não à publicação de um determinado artigo. No caso de discordância entre pareceristas, um terceiro nome pode ser chamado, ou ainda a Comissão Editorial ou os organizadores do número/dossiê temático assumem uma posição favorável ou contrária à publicação de um texto submetido.

Se, por um lado, essa é a melhor metodologia desenvolvida até o momento, ela apresenta algumas dificuldades. A primeira delas diz respeito ao tempo dedicado pela Comissão Editorial à leitura e análise dos artigos submetidos. Em 2015, a Comissão Editorial conta com três editores: a editora-chefe, autora deste artigo, que além das atribuições científicas trata de aspectos administrativos da editoração; e as professoras doutoras Onici Claro Flôres e Rosane Cardoso, ambas pesquisadoras e docentes do PPGL Unisc, que acumulam as demandas da Signo com sua atuação na docência e na pesquisa. Portanto, o tempo dedicado à revista pela Comissão Editorial é um dos desafios inerentes à qualificação da revista.

Até o presente, os editores entendem que a revisão cega implica 0 aceite da submissão de artigos, independentemente da titulação dos autores, partindo do princípio de que se o artigo possui qualidade, atestada pela revisão cega por pares, deve ser publicado, ainda que seu autor seja mestrando ou doutorando. Por outro lado, o número crescente de artigos submetidos à revista, muitos deles sem a qualidade necessária para prosseguimento no processo de avaliação, vai de encontro a essa posição, pois a titulação poderia ser uma forma de selecionar as submissões a priori. Uma das alternativas adotada nos últimos anos é o convite a organizadores reconhecidos pelo seu conhecimento em uma determinada temática, contribuindo assim no processo de leitura, avaliação e qualificação dos artigos submetidos. Outra ação implementada é a expansão do Conselho Editorial e a ampliação do número de consultores ad hoc, o que tem contribuído para distribuir o volume de trabalho entre um número maior de avaliadores. Cumpre lembrar ao leitor desavisado que a atuação em Conselhos Editoriais e consultoria ad hoc nas revistas de Letras e Linguística do Brasil, até onde vai nosso conhecimento, é sempre um trabalho não remunerado, que conta com 0 comprometimento, boa vontade e profissionalismo dos pesquisadores.

Outro desafio para a próxima década é a internacionalização da revista, um desafio que se desdobra em vários - nem tão pequenos - desafios, que são apresentados de forma sucinta na sequência.

- Layout. O volume 39, n. 67, de jul/dez de 2014 da Signo apresenta os artigos com novo layout, mais moderno e próximo ao usado pelas revistas internacionais, contendo na primeira página todas as informações para citação do artigo (volume, número, página inicial e final, ano de publicação, ISSN, DOI, endereço virtual da revista, endereço eletrônico de contato do(s) autor(es), afiliação dos autores, data de recebimento e aceite do artigo, política de acesso livre) bem como título, resumo e palavras-chave tanto na língua em que o artigo está escrito quanto em inglês. O novo layout procura se distanciar cada vez mais do formato de um texto editado em um processador de texto do tipo Word, por exemplo, ao mesmo tempo em que cria uma identidade visual própria dos artigos publicados na revista Signo. 
- Endogenia. O conceito de endogenia, quando relacionado aos periódicos científicos, tem passado por várias reformulações nos últimos 10 anos. Se durante um período era considerada endógena uma publicação que apresentava um grande número de artigos de autoria de professores e estudantes da instituição mantenedora do periódico, hoje fala-se em endogenia quando uma publicação apresenta a maioria de autores de um mesmo estado ou região do país. Assim, a revista Signo tem procurado ampliar cada vez mais a divulgação de suas chamadas de artigos, para que pesquisadores de vários estados e países submetam artigos para a revista, participando de várias redes de difusão de chamadas de artigos. Outra ação em andamento é a ampliação e a diversificação das instituições e dos países de origem dos membros do Conselho Editorial da Signo.

- Tradução. O software SEER, utilizado na editoração da Signo, permite a escolha do idioma de leitura da página, de acordo com a preferência do usuário (ver aba à direita da página em http://online.unisc.br/seer/index.php/signo/index).

Desde 2014, o site da Signo vem sofrendo adequações para que o leitor possa acessar o site em inglês e espanhol. Atualmente, o sumário da revista pode ser lido tanto em português quanto em inglês, mas é necessário costumizar ainda várias páginas para que o site seja considerado, em um primeiro momento, bilíngue (português / inglês) e futuramente trilíngue (português / inglês / espanhol). Com relação à língua em que os artigos estão escritos, Signo aceita e estimula a submissão de artigos em línguas estrangeiras, em especial, inglês e espanhol, ainda que a predominância dos artigos submetidos seja em língua portuguesa. Os editores da Signo têm consciência de que a plena internacionalização da revista implicaria na adoção da língua inglesa como padrão para os artigos, mas esse é um cenário ainda distante, em face dos artigos que ora são submetidos e publicados.

- Periodicidade. Nos últimos 10 anos, a revista Signo manteve sua periodicidade constante, com dois números anuais, um por semestre, e, eventualmente, um terceiro número especial, com temática específica, publicando em torno de 30 a 40 artigos por ano. Entretanto, em virtude das orientações de alguns indexadores internacionais, ao longo do ano de 2015 haverá uma adequação na data de lançamento dos números da revista, que passarão a ser lançados no primeiro mês do período de circulação, ou seja,em julho, se o número diz respeito ao segundo semestre do ano, ou em janeiro, se o número corresponde ao primeiro semestre.

Os editores da Signo acompanham as discussões da ABEU - Associação Brasileira de Editoras Universitárias, da ABEC - Associação Brasileira de Editores Científicos e dos Encontros de Editores da Área de Letras e Linguística da Capes. Nesses fóruns, é recorrente o tópico da profissionalização de pessoal técnico de apoio na editoração dos periódicos, uma vez que o fluxo informatizado de editoração exige conhecimentos específicos. Muitas revistas contam com o auxílio de bolsistas e estudantes, mas essa é uma solução que implica em grande rotatividade do pessoal de apoio. Por isso, é necessário investir na formação e profissionalização técnica de pessoas que possam auxiliar os editores científicos. Nesse sentido, vale destacar a contratação e manutenção na Unisc de um profissional com conhecimento técnico sobre o SEER, $\mathrm{DOI}$, metadados e demais conceitos inerentes à publicação científica.

Outro tópico recorrente nos fóruns supracitados é a sustentabilidade das revistas. A fim de gerar recursos financeiros, algumas revistas cobram valores quando da submissão dos artigos ou quando do aceite para publicação, ou ainda cobram taxas para o acesso à versão completa do artigo (ou seja, não são revistas de acesso livre ou open accessjournals). Graças ao apoio da Unisc, dos membros do Conselho Editorial e dos consultores ad hoc, Signo tem-se mantido um periódico de acesso livre, que não cobra valores no processo de submissão e publicação de artigos.

Ainda que sejam vários os desafios e que por vezes não saibamos ao certo como enfrentá-los, a história de 40 anos da revista Signo mostra que o comprometimento de vários profissionais ligados à 
revista tem escrito uma trajetória de sucesso. Retomando a história desses 40 anos, vemos que a semente plantada à época germinou, cresceu e floresceu, e que cabe a nós e aos futuros colaboradores da Signo continuarmos trabalhando na adubação, na irrigação e na poda, para que os próximos 40 anos sejam de novas conquistas.

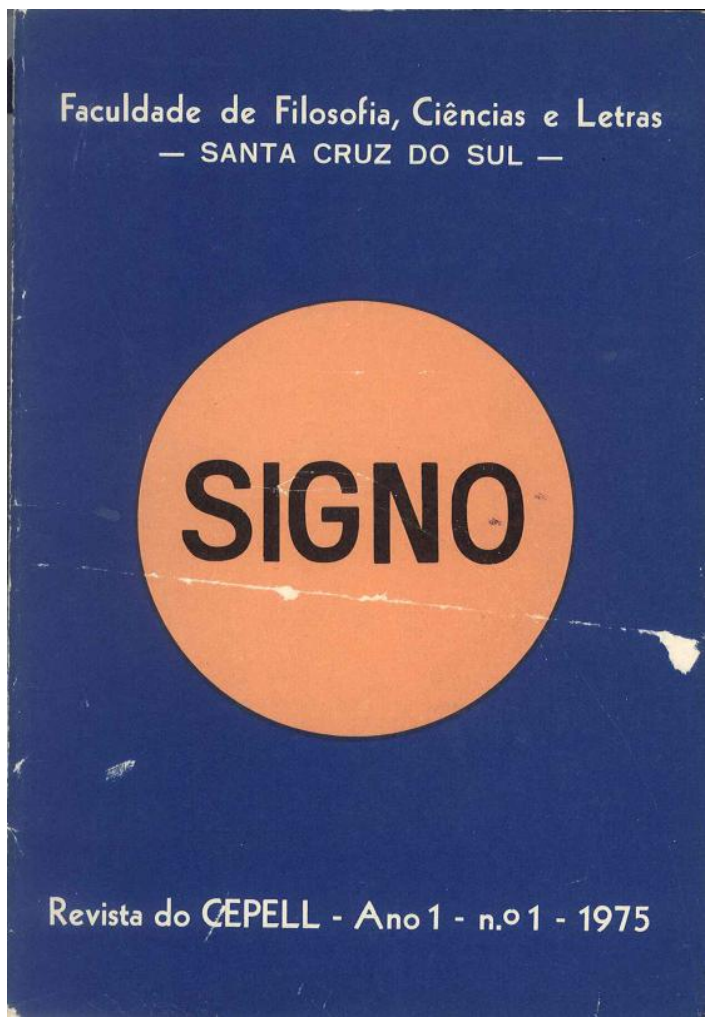

Fig. 1 - Capa da revista Signo, número 1, vol. 1, 1975

\section{Referências}

BONINI, A. Qualis de Letras/Linguística: uma análise de seus fundamentos. R B P G, v. 1, n. 2, p. 141-159, nov. 2004. Disponível em http://ojs.rbpg.capes.gov.br/index.php/rbpg. Acesso em 12/03/2015.

BRASIL. Ministério da Ciência, Tecnologia e Inovação. Instituto Brasileiro de Informação em Ciência e Tecnologia. Brasília: MCTI, 2015. Disponível em http://www.ibict.br/pesquisadesenvolvimento-tecnologico-e-inovacao/sistemaeletronico-de-editoracao-de-revistas-seer. Acesso em 09/03/2015.

BRASIL. Ministério da Educação. Coordenação de Aperfeiçoamento de Pessoal de Nível Superior. Brasília: MEC, 2015. Disponível em http://www.capes.gov.br/ . Acesso em 12/03/2015.
CROSSREF. CrossRef.org Disponível em http://www.crossref.org/01company/02history.html Acesso em 17/04/2015.

KIPPER, M. H.; RIZZATO, E. P.; VOGT, O. P. UNISC. a construção de uma universidade comunitária. Santa Cruz do Sul: EDUNISC, 2014. [recurso eletrônico]

LI, D.; AGHA, L. Big names or big ideas: Do peerreview panels select the best science proposals? Science, vol. 348, no. 6233, pp. 434-438. Disponível em

http://www.sciencemag.org/content/348/6233/434.full . Acesso em 28/04/2015. DOl: 10.1126/science.aaa0185

MACIEL, M. G. de L.; ROCHA NETO, I. O Qualis Periódicos na percepção de um grupo de coordenadores de programas de pós-graduação. RBPG, Brasília, v. 9, n. 18, p. 639 - 659, dezembro de $2012 . \quad$ Disponível em http://ojs.rbpg.capes.gov.br/index.php/rbpg. Acesso em 12/03/2015.

UNISC. Plano de Desenvolvimento Institucional. PDI V 2013-2017. Aprovado em maio 2013. 292p. Disponível em www.unisc.br . Acesso em 01/04/2015.

UNISC. Programa de Pós-Graduação em Letras. Santa Cruz do Sul: UNISC, 2015. Disponível em http://www.unisc.br/portal/pt/cursos/mestrado/mestrad o-em-letras/apresentacao/objetivos.html . Acesso em $11 / 03 / 2015$.

UNISC. Signo. Santa Cruz do Sul: UNISC, 2015. Disponível em http://online.unisc.br/seer/index.php/signo . Acesso em 12/03/2015.

ZANOTTO, M. S. As múltiplas leituras da 'metáfora': desenhando uma metodologia de investigação. Signo. Santa Cruz do Sul, v. 39, n. 67, p. 3-17, jul./dez. 2014. http://dx.doi.org/10.17058/signo.v39i67.5409 